\title{
Simulasi Penggunaan Lahan dan Transportasi Massal untuk Pemodelan Pelayanan Jalan di Koridor Jalan Godean
}

\section{Okta Fajar Saputra ${ }^{1}$, M. Pramono Hadi ${ }^{2}$ dan Suharyadi ${ }^{2}$}

Pusat Studi Ekonomi dan Kebijakan Publik (PSEKP) Universitas Gadjah Mada Yogyakarta, Indoensia ${ }^{1}$

Fakultas Geografi Universitas Gadjah Mada Yogyakarta, Indonesia ${ }^{2}$

Email Koresponden: okta fajar@mail.ugm.ac.id

Diterima : April 2017 ; Direvisi : Juli 2017; Dipubikasikan: September 2017

(C) 2017 Fakultas Geografi UGM dan Ikatan Geograf Indonesia.

\begin{abstract}
Abstrak Rendahnya tingkat pelayanan jalan menjadi salah satu permasalahan yang ada di Koridor Jalan Godean. Permasalahan tersebut dapat di atasi dengan pengendalian penggunaan lahan serta penyediaan angkutan massal. Penelitian ini dilakukan untuk memodelkan tingkat pelayanan jalan jika terjadi perubahan penggunaan lahan sesuai dokumen Rencana Detail Tata Ruang (RDTR) serta pemodelan jika dilakukan pembangunan angkutan massal. Metode yang digunakan dalam penelitian ini yaitu metode kuantitatif. Metode kuantitatif digunakan untuk menghitung nilai VCR (Volume - Capacity Ratio) eksisting, nilai VCR dengan pemodelan pembangunan sesuai RDTR, ketentuan nilai intensitas bangunan ideal, dan nilai VCR dengan pemodelan pembangunan angkutan massal. Hasil penelitian menunjukkan bahwa tingkat pelayanan jalan pada kondisi eksisting masih sangat rendah dan jauh dari kondisi ideal. Kondisi ini diperakan sama dengan yang terjadi di masa mendatang, bahkan tingkat pelayanan jalan di sebagian segmen jalan akan semakin menurun. Potensi volume kendaraan tidak dapat ditampung oleh ruas jalan yang ada. Ketentuan intensitas bangunan perlu diturunkan sebesar 44,5\% di segmen 2 dan sebesar 74,9\% di segmen 4 dari nilai koefisien nilai bangunan (KLB) yang sudah direncanakan. Selain menurunkan intensitas bangunan, tingkat pelayanan jalan dapat ditingkatkan dengan pembangunan angkutan massal. Hasil pemodelan menggunakan angkutan massal menunjukkan bahwa moda transportasi yang masih memungkinkan untuk dibangun di Koridor Jalan Godean yaitu monorail dan trem dengan model jalur trem tidak eksklusif. Namun, jika pembangunan angkutan massal yang dipilih berupa trem, maka masih diperlukan penurunan ketentuan intensitas bangunan sekitar 37,8\% di segmen 2 dan sekitar 68,78\% di segmen 4 dari nilai KLB yang sudah direncanakan.
\end{abstract}

Kata Kunci: Tingkat Pelayanan Jalan, Pemodelan Transportasi, Angkutan Massal, Simulasi Penggunaan Lahan

\begin{abstract}
The low road service of Godean Corridor has become problematic. Since this problem can be dealt with by controlling land use and providing feasible mass transportation, this research aimed to model the level of road service if the land use change occurred in line with the Detailed Spatial Plan (DSP) and in the case of mass transportation development. The research used a quantitative method to calculate the existing Volume-Capacity Ratio (VCR), the VCR in DSP-based development model, the prerequisites for ideal building intensity, and the VCR in mass transportation-based development model. The results showed that the current road service was very low and far from ideal. This condition was estimated to persist in the future. The road services in some segments were also estimated to decline continuously. The current road could not accommodate the existing and potential of the traffic volume. The stipulation of building intensity has to be reduced by $44.5 \%$ in segment 2 and $74.9 \%$ in segment 4 from the previously planned building value coefficient. Aside from reducing the building intensity, the road service can also be increased by developing mass transportation. The results of mass transportation modeling showed that the feasible modes of transportation on the corridor were monorail and tram with non-exclusive tramway model. However, if the selected transportation is tram, then the building intensity has to be reduced by $37.8 \%$ in segment 2 and $68.78 \%$ in segment 4 from the predefined building value coefficient.
\end{abstract}

Keywords: Road Service Level, Transportation Modeling, Mass Transportation, Land Use Simulation

\section{PENDAHULUAN}

Permasalahan transportasi di wilayah perkotaan utamanya adalah kemacetan (Zuharnen, 1992). Kemacetan umumnya disebabkan jumlah kendaraan yang lewat melebihi batas maksimum yang dapat ditampung (Munardy dkk, 2005). Faktor lainnya yang menyebabkan permasalahan transportasi di perkotaan yaitu pembangunan yang tidak terkendali (Handoyo dkk., 2014). Hal tersebut dikarenakan setiap guna lahan danintensitaspemanfaatanlahannyaakan menghasilkan pergerakan (trip generation) serta menarik pergerakan (trip attraction) (Tamin, 2000; Prakoso dan Mutaali, 2005). Perkembangan kota yang tidak terkendali akan menyebabkan berbagai permasalahan lain yang tidak terkendali pula (Cahyadi dkk., 2012; Cahyadi et al., 2013; Wardani dkk., 2016), salah satunya transportasi.

Salah satu upaya untuk mengatasi permasalahan kemacetan akibat adanya bangkitan dan tarikan dari penggunaan lahan di suatu wilayah adalah konsep Transport Demand Management (TDM) 
atau Manajemen Kebutuhan Transportasi (MKT). Manajemen Kebutuhan Transportasi bertujuan untuk membatasi jumlah perjalanan dengan cara mengelola komponen-komponen yang mampu mempengaruhi jumlah pergerakan. Konsep MKT yang dapat diterapkan di negara-negara berkembang yaitu pengendalian penggunaan lahan (Cracknell, 2000).

Solusi lain dari permasalahan kemacetan adalah penyediaan sarana dan prasarana transportasi massal. Penyediaan angkutan massal merupakan solusi yang efektif karena mampu mengurangi kepadatan lalulintas. Angkutan massal lebih efisien menggunakan prasarana dibandingkan dengan angkutan pribadi (Tamin, 2000).

Jalan Godean sebagai salah satu akses utama yang menghubungkan Kabupaten Sleman (daerah pinggiran) dengan Kota Yogyakarta (pusat kota) memiliki penggunaan lahan yang bervariasi dan intensif di sepanjang koridor jalannya. Penggunaan lahan yang ada di koridor Jalan Godean meliputi fungsi pelayanan, perdagangan, dan perkantoran. Kondisi tersebut merupakan konsekuensi dari koridor penghubung daerah pinggiran dan pusat kota (Rachmawati dan Kurniawan, 2006; Indrawati, 2009; Ekartaji dkk., 2014). Hal tersebut memberikan beban lalu lintas bagi Jalan Godean. Jalan Godean memiliki beban perjalanan penglaju dari Peri-urban Kabupaten Sleman menuju Kota Yogyakarta, juga bangkitan dan tarikan perjalanan dari pemanfaatan lahan yang ada di sepanjang koridor jalannya (Rachmawati, 2008). Hal tersebut menyebabkan permasalahan kemacetan di Jalan Godean.

Solusi dari permasalahan kemacetan di koridor Jalan Godean yaitu berupa pengendalian pemanfaatan lahan dan penyediaan sarana transportasi massal. Pemanfaatan lahan di koridor Jalan Godean diatur agar potensi bangkitan dan tarikan transportasinya sesuai dengan kapasitas jalan yang tersedia. Berdasarkan uraian tentang konsep perencanaan transportasi di wilayah perkotaan, maka tujuan dari penelitian tesis ini adalah (1) mengkaji tingkat pelayanan jalan eksisting di koridor Jalan Godean, (2) memodelkan kondisi tingkat pelayanan jalan jika intensitas bangunan berdasarkan Dokumen RDTR di koridor Jalan Godean diterapkan sepenuhnya, dan (3) memodelkan perubahan tingkat pelayanan jalan di koridor Jalan Godean dengan simulasi pembangunan angkutan massal.

Ditinjau dari sistem transportasi, pengendalian pemanfaatan ruang juga merupakan salah satu cara dalam Manajemen Kebutuhan Transportasi (MKT). Manajemen Kebutuhan Transportasi merupakan cara untuk mempengaruhi perilaku pergerakan masyarakat untuk mengurangi nilai kebutuhan pergerakan. Manajemen Kebutuhan Transportasi dilakukan dengan cara menyebarkan kebutuhan akan pergerakan secara spasial dan waktu (Orski, 1998 dalam Tamin, 2000).
Terdapat perbedaan antara konsep kebijakan transportasi secara konvensional dan MKT. Konsep kebijakan konvensional yaitu menyediakan prasarana transportasi sesuai kebutuhan yang ada agar mencapai titik seimbang. Upaya penyeimbangan antara kebutuhan dan suplai dilakukan meskipun kondisi nilai kebutuhan akan transportasi tersebut sudah melebihi batas daya dukung lingkungan, sosial, maupun operasional. Kebijakan dengan pendekatan MKT yaitu mengatur kebutuhan transportasi yang ada agar tidak melebihi batas daya dukung lingkungan, sosial, dan operasional. Upaya pengaturan nilai kebutuhan transportasi tersebut juga diiringi dengan penyediaan prasarana transportasi, penyediaan prasaranya dilakukan dengan sangat selektif agar tidak melebihi batas daya dukung (Tamin, 2000).

Konsep MKT mampu menyeimbangkan antara kebutuhan dan ketersediaan prasarana transportasi tanpa melampaui batas daya dukung lingkungan, sosial, dan operasional. Kebijakan dalam MKT yaitu berupa pengaturan atau pergeseran waktu terjadinya perjalanan, perubahan moda, perubahan rute atau lokasi, serta perubahan lokasi tujuan. MKT dilakukan untuk penurunan jumlah perjalanan, penurunan jumlah kendaraan bergerak, dan dekonsentrasi arus lalu-lintas. Konsep dari MKT dapat dilihat pada Gambar 1.

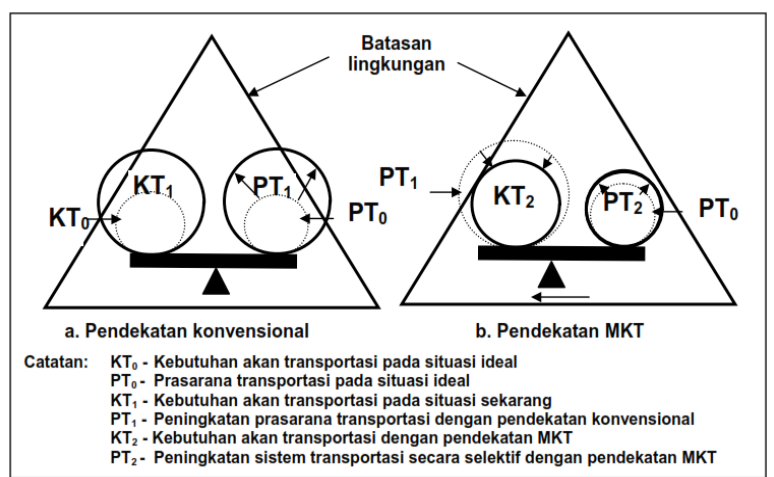

Sumber: Ohta (1998 dalam Tamin 2000)

Gambar 1. Konsep Kebijakan Transportasi Konvensional dan MKT

Prinsip dari MKT bukanlah membatasi pembangunan, namun untuk mengatur pelaksanaan pembangunan agar dampak-dampak positif dari pembangunan dapat dioptimalkan dan dampakdampak negatif dapat diminimalkan (Titania, 2008). Stein (1993, dalam Titania, 2008) menjelaskan bahwa salah satu strategi dalam MKT yaitu penerapan batas/ trip ceiling pada pembangunan baru. Trip ceiling dapat mengurangi jumlah pergerakan menggunakan pembatasan bangkitan dan tarikan pada suatu wilayah. Bentuk kegiatan dan intensitasnya diatur agar dapat sesuai dengan kemampuan pelayanan wilayahnya. 
Tingkat pelayanan jalan dapat dilihat daribeberapa indikator yaitu kecepatan lalu lintas (jalan luar kota), kecepatan rata-rata (jalan perkotaan), perbandingan antara volume lalu lintas dan kapasitas jalan atau VCR (Volume - Capacity Ratio), kepadatan lalu lintas, dan kecelakaan lalu lintas (Peraturan Menteri Perhubungan Nomor KM 14 Tahun 2006). Tingkat pelayanan jalan juga memiliki beberapa kelas atau klasifikasi mulai dari kelas A hingga kelas F, di mana kelas A merupakan kelas untuk jalan yang memiliki tingkat pelayanan paling baik, sedangkan kelas F merupakan kelas untuk jalan yang memiliki tingkat pelayanan paling buruk. Standar penilaian tingkat pelayanan jalan berbedabeda untuk setiap kelas jalan. Tabel 1 menunjukkan standar penilaian tingkat pelayanan jalan untuk kelas jalan kolektor primer.

Tabel 1. Karakteristik Tingkat Pelayanan Jalan Kolektor Primer

\begin{tabular}{|c|c|}
\hline Tingkat Pelayanan & Karakteristik Operasi Terkait \\
\hline$A$ & $\begin{array}{ll}\text { - } & \text { Kecepatan Lalulintas } \geq 100 \mathrm{Km} / \mathrm{Jam} \\
\text { - } & V C R \leq 0,3\end{array}$ \\
\hline$B$ & $\begin{array}{l}\text { - } \quad \text { Awal dari kondisi arus stabil } \\
\text { - } \quad \text { Kecepatan lalulintas sekitar } 90 \mathrm{Km} / \mathrm{Jam} \\
\text { - } \quad V C R \leq 0,5\end{array}$ \\
\hline$C$ & $\begin{array}{ll}\text { - } & \text { Arus stabil } \\
\text { - } & \text { Kecepatan lalulintas } \geq 75 \mathrm{Km} / \mathrm{Jam} \\
\text { - } & V C R \leq 0,75\end{array}$ \\
\hline$D$ & $\begin{array}{ll}\text { - } & \text { Mendekati arus tidak stabil } \\
\text { - } & \text { Kecepatan lalulintas sekitar } 60 \mathrm{Km} / \mathrm{Jam} \\
\text { - } & V C R \leq 0,9\end{array}$ \\
\hline E & $\begin{array}{l}\text { - } \quad \text { Arus pada tingkat kapasitas dan tidak stabil } \\
\text { - } \quad \text { Kecepatan perjalanan lalulintas sekitar } 50 \mathrm{Km} / \mathrm{Jam} \\
\text { - } \quad V C R \leq 1\end{array}$ \\
\hline$F$ & $\begin{array}{l}\text { - } \quad \text { Arus tertahan, kondisi terhambat (congested) } \\
\text { - } \quad \text { Kecepatan lalulintas }<50 \mathrm{Km} / \mathrm{Jam} \\
\text { - } \quad V C R>1\end{array}$ \\
\hline
\end{tabular}

Sumber: Peraturan Menteri Perhubungan Nomor KM 14 Th. 2006

\section{METODE PENELITIAN}

Penelitian ini menggunakan pendekatan permintaan (demand) dan penyediaan (supply). Pendekatan penyediaan digunakan untuk menghitung kapasitas jalan yang ada di Koridor Jalan Godean serta kapasitas angkut transportasi massal hasil pemodelan. Pendekatan permintaan dilakukan untuk menghitung potensi nilai pergerakan baik akibat penggunana lahan maupun pergerakan yang melakukan perjalan menerus di Koridor Jalan Godean. Kedua pendekatan tersebut digunakan untuk menghitung VCR di Koridor Jalan Godean. Berdasarkan hasil perhitungan VCR, selanjutnya dapat ditentukan rumusan kebijakan yang paling optimal di Koridor Jalan Godean.

Daerah kajian dalam penelitian ini mencakup sebagian wilayah administrasi Kabupaten Sleman, Kabupaten Bantul dan Kota Yogyakarta. Objek kajian dalam penelitian ini adalah segmen-segmen jalan di Koridor Jalan Godean (Gambar 2). Koridor Jalan Godean yang masuk dalam kajian adalah Jalan Kyai Mojo (Persimpangan dengan Jalan Hos Cokroaminoto) hingga Jalan Godean (Persimpangan dengan Ringroad Barat). Jalan Godean yang dikaji dibagi menjadi beberapa segmen jalan. Hasil pembagian segmen jalan tersebut yaitu terdiri dari (1) Simpang Jln. Hos Cokroaminoto - Simpang Mirota Godean, (2) Simpang Mirota Godean - Simpang SPBU 44.555.13 Banyuraden, (3) Simpang SPBU 44.555.13 Banyuraden - Simpang Jln. Kabupaten, dan (4) Simpang Jln. Kabupaten Simpang Jln. Ringroad Barat. 


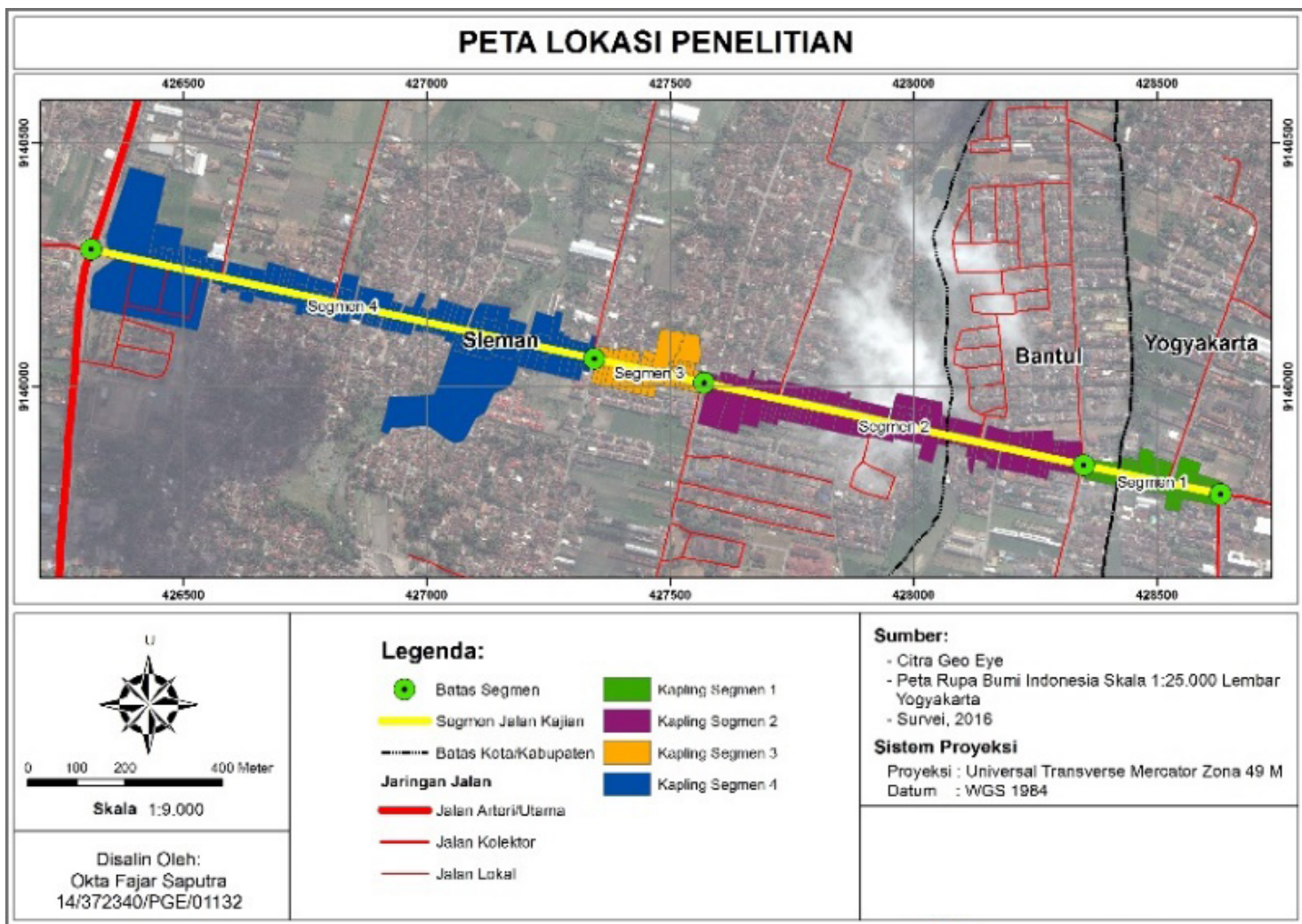

Gambar 2. Peta Lokasi Penelitian

\section{HASIL DAN PEMBAHASAN}

\section{Tingkat Pelayanan Jalan Eksisting}

Hasil kajian menunjukkan bahwa empat segmen jalan yang diteliti memiliki nilai VCR yang sangat tinggi. Tiga dari empat segmen yang diteliti memiliki nilai VCR lebih dari 1. Bahkan nilai rata-rata VCR dari keempat segmen jalan tersebut mencapai 1,04. Nilai VCR tertinggi berada di segmen 2 yaitu dengan nilai mencapai 1,15 . Segmen lainnya yang memiliki VCR lebih dari 1 yaitu segmen 1 dan segmen 3 . Segmen 1 memiliki VCR 1,03, sedangkan segmen 3 memiliki VCR 1,07. Tingginya VCR di ketiga segmen tersebut menyebabkan tingkat pelayanan jalannya masuk dalam kategori F.

Segmen jalan yang memiliki nilai VCR paling rendah yaitu segmen 4 . Hal tersebut karena segmen 4 memiliki volume terendah. Selain itu, segmen 4 memiliki kapasitas jalan yang paling tinggi dibandingkan segmen lainnya. Meskipun segmen 4 memiliki VCR terendah, nilai VCR di segmen 4 termasuk tinggi, yaitu mencapai 0,93 . Nilai VCR tersebut membuat segmen 4 masuk dalam kategori tingkat pelayanan E.

Batas toleransi nilai VCR yang diperbolehkan di Jalan Godean adalah 0,7, namun nilai VCR pada kondisi eksisting sudah mencapai 0,93 hingga 1,15 . Hal tersebut menunjukkan bahwa tingkat pelayanan jalan di Jalan Godean pada kondisi eksisting masih sangat rendah dan jauh dari ideal. Oleh karenanya perlu diterapkan suatu kebijakan agar permasalahan lalulintas dapat teratasi. Hasil perhitungan nilai VCR dan tingkat pelayanan jalan di Jalan Godean dapat dilihat pada Tabel 2.

Tabel 2. Perhitungan VCR dan Tingkat Pelayanan Jalan Eksisting

\begin{tabular}{ccccc}
\hline Segmen & Total SMP & Kapasitas & VCR & Tingkat Pelayanan Jalan \\
\hline 1 & 3220,9 & 3137,2 & 1,03 & $\mathrm{~F}$ \\
2 & 3597,3 & 3137,2 & 1,15 & $\mathrm{~F}$ \\
3 & 3468,7 & 3244,2 & 1,07 & $\mathrm{~F}$ \\
\hline
\end{tabular}

Sumber: Hasil Analisis Data (2017)

Keterangan: SMP = Satuan Mobil Penumpang 


\section{Pemodelan Tingkat Pelayanan Jalan Berdasarkan Dokumen RDTR}

Salah satu perencanaan transportasi yang dapat dilakukan di wilayah perkotaan adalah pengendalian pemanfaatan lahan. Pengendalian pemanfaatan lahan menjadi salah satu komponen untuk perencanaan transportasi karena setiap jenis penggunaan lahan dengan intensitas tertentu akan menghasilkan bangkitan dan tarikan transportasi. Dokumen perencanaan yang mengatur perencanaan penggunaan lahan dan intensitas pemanfaatannya adalah RDTR (Rencana Detail Tata Ruang).

Perubahan tingkat pelayanan jalan berdasarkan RDTR merupakan pemodelan tingkat pelayanan jalan akibat adanya penyesuaian nilai volume kendaraan jika pembangunan diterapkan sesuai RDTR. Pemodelan volume kendaraan dilakukan berdasarkan luas persil dan jenis pemanfaatan lahan sesuai RDTR. Hasil pemodelan tersebut menghasilkan nilai volume perjalanan lokal. Selain menggunakan variabel volume kendaraan, diperlukan variabel kapasitas jalan. Diasumsikan bahwa tidak dilakukan pembangunan ataupun perubahan kondisi jalan, sehingga variabel kapasitas jalan yang digunakan adalah nilai kapasitas eksisting.

Berdasarkan nilai VCR dari masing-masing segmen diketahui bahwa segmen 2 dan segmen 4 memiliki nilai VCR yang sangat tinggi. Nilai VCR yaitu 1,12 untuk segmen 2 dan 1,38 untuk segmen 4 . Tingginya nilai VCR tersebut menunjukkan bahwa tingkat pelayanan jalan di kedua segmen tersebut masuk kategori F. Berbeda dengan segmen 2 dan segmen 4, nilai VCR di segmen 1 relatif sedang, yaitu 0,58 . Nilai VCR tersebut menunjukkan bahwa hasil pemodelan tingkat pelayanan di segmen 1 berubah menjadi cukup baik. Tingkat pelayanan jalan di segmen 1 masuk dalam kategori C. Segmen yang memiliki nilai VCR paling baik hasil pemodelan adalah segmen 3. Nilai VCR hasil pemodelan di segmen 3 yaitu 0,34. Tingkat pelayanan jalan hasil pemodelan di segmen 3 masuk dalam kategori B.

Kondisi tingkat pelayanan jalan setelah dilakukan simulasi sesuai RDTR berbeda dengan kondisi eksisting. Berdasarkan hasil simulasi, beberapa segmen jalan tingkat pelayanan jalan hasil pemodelan menjadi lebih baik, tetapisebagianlainnyajustrukondisinya cenderung sama bahkan lebih buruk. Tingkat pelayanan jalan hasil pemodelan di segmen 2 kondisinya cenderung sama dengan eksisting. Tingkat pelayanan jalan di segmen 2 masuk kategori F baik pada kondisi eksisting maupun hasil pemodelan. Tidak jauh berbeda dengan segmen 2, hasil pemodelan segmen 4 juga memiliki tingkat pelayanan jalan kategori F. Namun kondisi tersebut menunjukkan penurunan tingkat pelayanan jalan, karena pada kondisi eksisting tingkat pelayanan jalan di segmen 4 masuk dalam kategori E.

Berbeda dengan segmen 2 dan segmen 4 , di segmen 1 dan segmen 3 tingkat pelayanan hasil pemodelannya justru lebih baik. Segmen 1 dan segmen 3 masingmasing memiliki tingkat pelayanan jalan kategori $\mathrm{C}$ dan B, jauh lebih baik dibandingkan kondisi eksisting. Dilihat dari nilai VCR juga jauh lebih baik. Nilai VCR di segmen 1 menurun dari semula 1,03 menjadi 0,58, sedangkan VCR di segmen 3 dari semula 1,07 menurun menjadi 0,34 . Lebih jelas tentang perbedaan nilai VCR pada kondisi eksisting dengan hasil pemodelan berdasarkan RDTR dapat dilihat pada Tabel 3.

Tabel 3. Perhitungan Perubahan VCR dan Tingkat Pelayanan Jalan Berdasarkan RDTR

\begin{tabular}{ccccccc}
\hline $\begin{array}{c}\text { Segmen } \\
\text { Jalan }\end{array}$ & $\begin{array}{c}\text { Total SMP } \\
\text { (model) }\end{array}$ & Kapasitas & $\begin{array}{c}\text { VCR } \\
\text { (model) }\end{array}$ & $\begin{array}{c}\text { Tingkat } \\
\text { Pelayanan Jalan } \\
\text { (model) }\end{array}$ & $\begin{array}{c}\text { VCR } \\
\text { (Eksisting) }\end{array}$ & $\begin{array}{c}\text { Tingkat Pelayanan } \\
\text { Jalan (Eksisting) }\end{array}$ \\
\hline 1 & 1833,67 & 3137,2 & 0,58 & $\mathrm{C}$ & 1,03 & $\mathrm{~F}$ \\
2 & 3510,16 & 3137,2 & 1,12 & $\mathrm{~F}$ & 1,15 & $\mathrm{~F}$ \\
3 & 1116,45 & 3244,2 & 0,34 & $\mathrm{~B}$ & 1,07 & $\mathrm{~F}$ \\
\hline
\end{tabular}

Sumber: Hasil Analisis Data (2017)

\section{Tingkat Pelayanan Jalan dengan Simulasi Pembangunan Angkutan Massal}

Banyak faktor yang dapat digunakan untuk menghitung efektivitas transportasi massal, namun faktor yang digunakan untuk pemodelan dalam penelitian ini adalah daya substitusi transportasi massal untuk mengurangi jumlah angkutan pribadi. Nilai volume yang digunakan untuk pemodelan yaitu nilai volume eksisting dan nilai volume hasil pemodelan pembangunan sesuai RDTR di segmen 2 dan segmen 4 . Pemilihan volume lalu-lintas tersebut sebagai data dasar perhitungan karena segmen-segmen tersebut memiliki nilai VCR yang jauh lebih besar dari VCR ideal. 
Angkutan massal yang dimodelkan dalam penelitian kali ini yaitu monorail, trem model 1 dan trem model 2. Trem model 1 yaitu jalur trem eksklusif yang hanya dapat digunakan oleh trem. Pemodelan pembangunan trem menggunakan model pertama tersebut menyebabkan lebar jalan dan/atau jumlah lajur efektif menjadi berkurang, sehingga kapasitas jalanpun juga menjadi berkurang. Trem model 2 yaitu jalur trem dapat dilalui pula oleh kendaraan lain. Pemodelan pembangunan trem menggunakan model kedua tersebut tidak menyebabkan lebar jalan dan/atau jumlah lajur efektif berkurang, namun volume lalulintas berubah. Besar penurunan nilai VCR dengan pemodelan angkutan massal dapat dilihat pada Gambar 3.

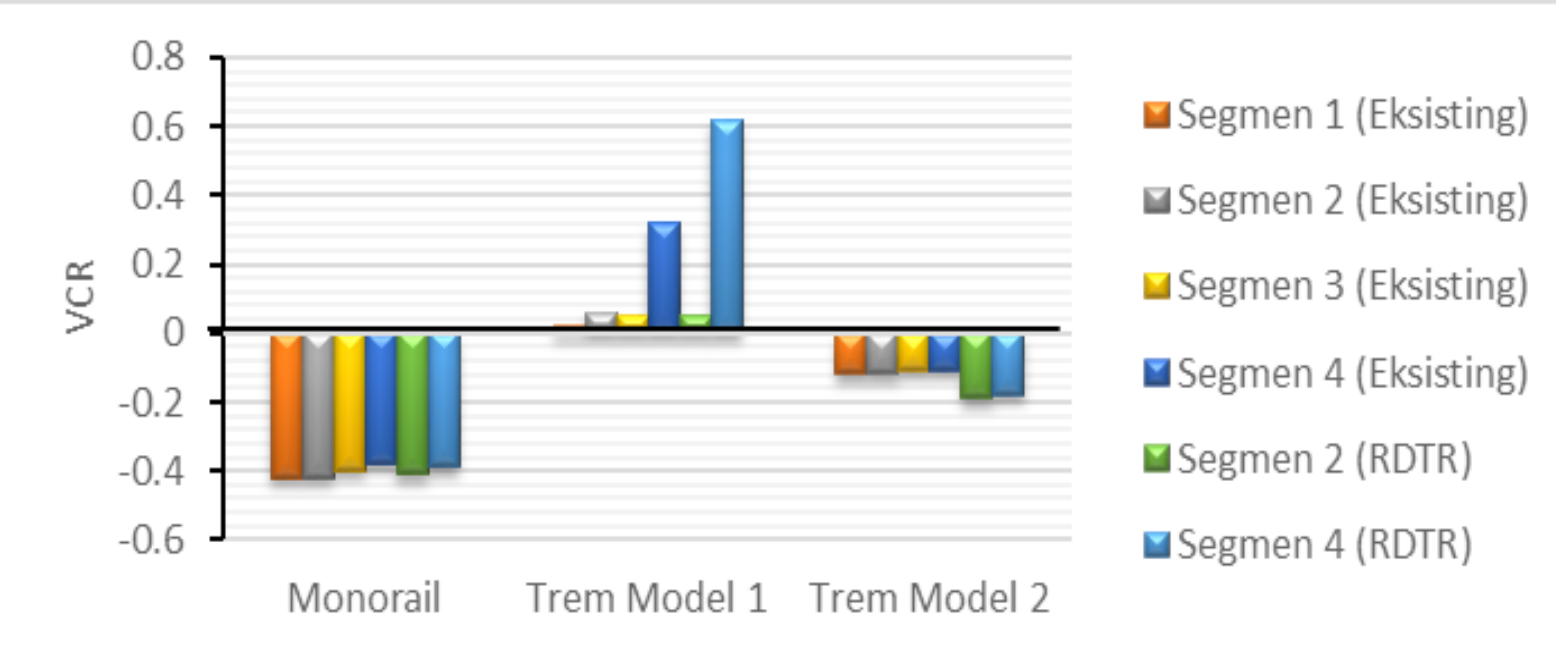

Gambar 4.1 Besar Perubahan Nilai VCR dengan Berbagai Pemodelan

Berdasarkan besar penurunan nilai VCR hasil pemodelan diketahui bahwa pembangunan monorail mampu mengurangi nilai VCR secara signifikan. Besaran penguranan nilai VCR oleh monorail jauh lebih besar dibandingkan trem model 1 maupun trem model 2. Besar penurunan nilai VCR dengan pemodelan monorail berkisar antara 0,38 hingga 0,42. Selain monorail, trem model 2 juga mampu menurunkan nilai VCR, meskipun tidak sebesar monorail. Besar nilai penurunan trem model 2 yaitu berkisar antara 0,11 hingga 0,19 .

Berbeda dengan monorail dan trem model 2, hasil pemodelan menggunakan trem model 1 justru menyebabkan nilai VCR meningkat. Peningkatan nilai VCR berkisar antara 0,02 hingga 0,62. Peningkatan sangat signifikan terjadi pada segmen 4 , baik pada penggunaan data dasar volume eksisting maupun volume hasil pemodelan pembangunan sesuai RDTR di Koridor Jalan Godeal. Peningkatan nilai VCR yang sangat signifikan di segmen 4 tersebut dikarenakan pengurangan kapasitas jalan yang cukup signifikan. Kelas lebar jalan di segmen 4 berkurang derastis akibat kebutuhan badan jalan untuk jalur trem. Dilihat dari besaran pengurangan nilai VCR tersebut, maka moda transportasi yang memungkinkan dibangun adalah monorail dan trem model 2.

\section{Pembangunan Angkutan Massal}

Hasil pemodelan menggunakan pembangunan angkutan massal menghasilkan nilai VCR baru. Nilai VCR setelah dilakukan pemodelan angkutan massal dapat dilihat pada Gambar 4. Berdasarkan nilai VCR hasil pemodelan diketahui bahwa tingkat pelayanan jalan menggunakan model monorail berubah menjadi ideal. Batas VCR ideal yaitu 0,7, sedangkan nilai VCR hasil pemodelan menggunakan monorail berkisar antara 0,55 hingga 0,73 . Hanya pada segmen 4 (RDTR) yang melebihi batas ideal. Nilai VCR di segmen 4 (RDTR) yaitu 0,99 . Hal tersebut menunjukkan bahwa moda transportasi monorail dapat direkomendasikan sebagai salah satu moda transportasi massal yang dapat dibangun di Koridor Jalan Godean untuk mengatasi permasalahan kemacetan yang ada. 


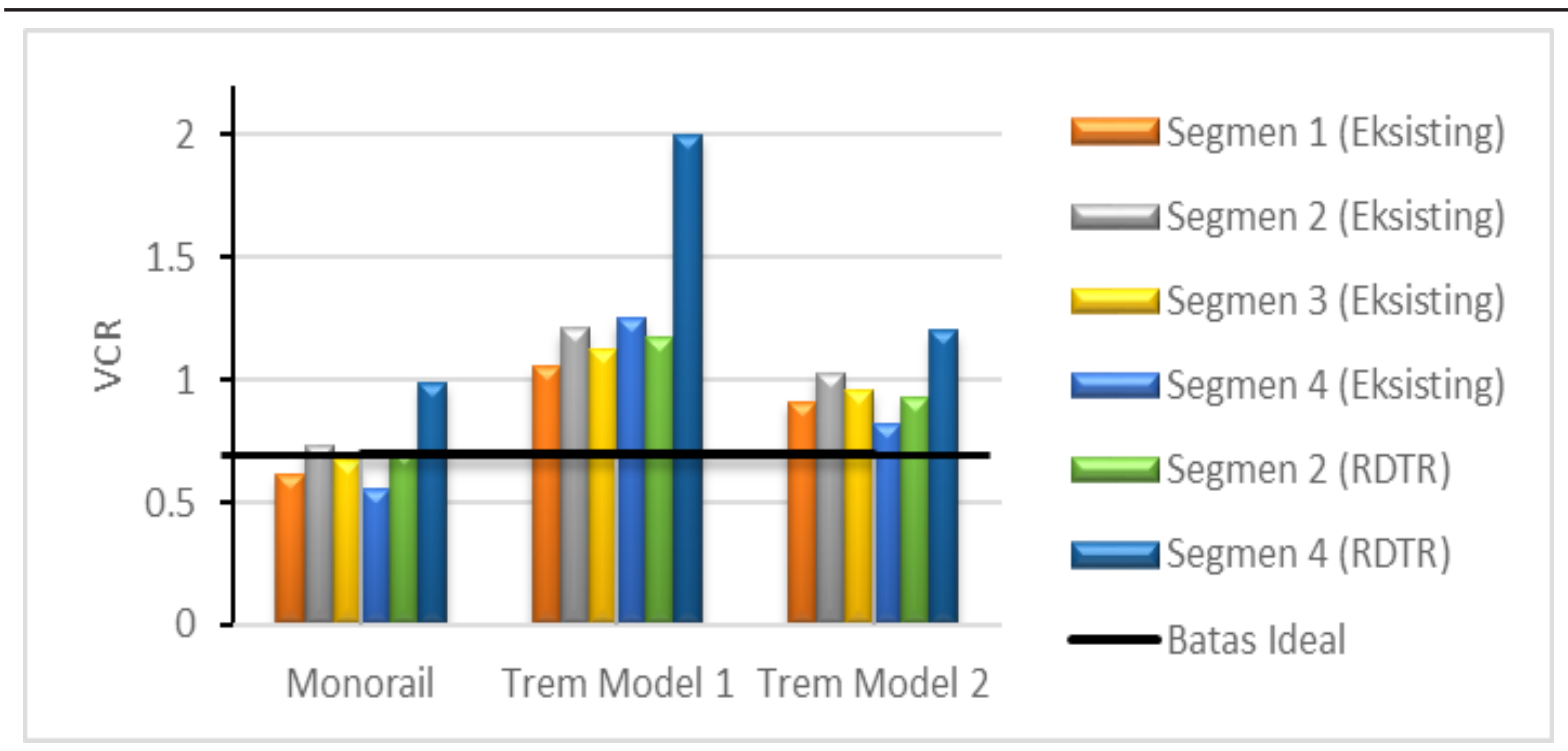

Gambar 4. Nilai VCR Setelah Dilakukan Erbagai Pemodelan

Pemodelan trem menunjukkan nilai VCR tidak ideal. Pemodelan menggunakan trem model 1 menyebabkan nilai VCR justru semakin jauh dari batas ideal. Pemodelan trem model 1 memiliki nilai VCR lebih besar dari 1 pada semua segmen. Nilai VCR hasil pemodelan trem model 1 yaitu berkisar antara 1,05 hingga 2. Berbeda dengan pemodelan trem model 1, nilai VCR hasil pemodelan trem model 2 nilainya lebih kecil dari 1. Hanya pada segmen 2 (eksisting) dan segmen 4 (RDTR) yang memiliki nilai VCR lebih dari 1. Hal tersebut menunjukkan bahwa trem model 2 mampu menurunkan nilai volume lalulintas hingga lebih kecil dibandingkan kapasitas jalannya. Nilai ratarata VCR hasil pemodelan menggunakan trem model 2 yaitu 0,98 . Berdasarkan berbagai kondisi tersebut, maka trem model 2 masih bisa dipertimbangkan untuk dibangun di Koridor Jalan Godean, meskipun belum mampu sepenuhnya mengatasi hambatan lalu-lintas.

Berdasarkan hasil perhitungan nilai VCR hasil pemodelan pembangunan angkutan massal, maka moda transportasi massal yang masih memungkinkan dibangun di Koridor Jalan Godean yaitu monorail dan trem model 2. Namun untuk penentuan moda transportasi yang lebih efektif di antara keduanya perlu mempertimbangkan aspek-aspek lainnya, seperti nilai investasi untuk pembangunan angkutan massal, biaya operasional, serta faktor keindahan kota.

\section{Pengaturan Ketentuan Intensitas Bangunan}

Pemodelan transportasi sesuai ketentuan RDTR menunjukan bahwa tingkat pelayanan jalan di Koridor Jalan Godean masih sangat rendah. Hal tersebut menunjukkan bahwa akan terjadi kemacetan di masa mendatang jika tidak ada peninjauan kembali tentang ketentuan rencana penggunaan lahan dan intensitasnya. Ketentuan intensitas bangunan yang diterapkan dalam regulasi RDTR masih terlalu tinggi. Ketentuan intensitas bangunan yang sudah direncanakan perlu diturunkan agar perencanaan pembangunan dapat sejalan dengan rencana transportasi.

Jenis penggunaan lahan yang nilai KLB-nya tidak diturunkan yaitu sawah, makam, pemerintahan, militer, dan fasilitas pelayanan seperti tempat ibadah, rumah sakit, dan sarana pendidikan. Penggunaan lahan yang nilai KLB-nya dapat diturunkan yaitu perdagangan dan jasa, perumahan, dan zona campuran. Segmen jalan yang dihitung nilai KLB idealnya yaitu segmen 2 dan segmen 4 . Hal tersebut dilakukan karena hasil pemodelan tingkat pelayanan jalan sesuai RDTR menunjukkan bahwa ketentuan KLB di kedua segmen tersebut masih terlalu tinggi. Tingkat pelayanan hasil pemodelan di segmen 2 dan segmen 4 masuk kategori paling buruk, bahkan lebih buruk dibandingkan kondisi eksisting.

Berdasarkan perhitungan nilai KLB ideal, diketahui bahwa perlu adanya penurunan ketentuan intensitas bangunan di segmen 2 dan segmen 4 . Penurunan ketentuan nilai KLB di Segmen 2 sekitar 44,5\% dari ketentuan KLB yang sudah direncanakan sebelumnya. Penentuan ketentuan KLB tersebut lebih kecil jika dibandingkan penurunan ketentuan KLB yang perlu dilakukan di segmen 4. Penurunan ketentuan KLB di segmen 4 yaitu sekitar 74,9\% dari ketentuan KLB yang sudah direncanakan sebelumnya.

Penurunan ketentuan KLB di Segmen 2 dilakukan untuk penggunaan lahan perdagangan dan jasa serta perumahan. Perumahan dengan KLB 1,8 perlu diturunkan menjadi 1 sedangkan perumahan dengan KLB 2,1 perlu diturunkan menjadi 1,2. Perdagangan dan jasa dengan KLB 2,5 perlu diturunkan menjadi 1,4, sedangkan perdagangan dan jasa dengan KLB 4,5 perlu diturunkan menjadi 2,5. Penurunan ketentuan 
KLB di Segmen 4 dilakukan untuk penggunaan lahan perumahan, perdagangan dan jasa, serta zona campuran. KLB di perumahan perlu diturunkan menjadi 0,5 . Penggunaan lahan berupa perdagangan dan jasa di segmen 4 perlu diturunkan KLB-nya menjadi 0,6 dari yang semula memiliki KLB 2,5. Penggunaan lahan untuk zona campuran perlu diturunkan ketentuan KLB-nya menjadi 0,5 dari yang semula memiliki KLB 2,1. Lebih jelas tentang penurunan ketentuan nilai KLB ideal dapat dilihat pada Tabel 4.

Tabel 4. Ketentuan KLB Ideal di Segmen 2 dan Segmen 4

\begin{tabular}{|c|c|c|c|c|}
\hline Segmen & Penggunaan Lahan & KLB sesuai RDTR & KLB Ideal & $\begin{array}{c}\text { Penurunan Nilai } \\
\text { KLB (\%) }\end{array}$ \\
\hline \multirow{7}{*}{ Segmen 2} & Makam & 0,1 & 0,1 & 0 \\
\hline & Pertanian & 0,1 & 0,1 & 0 \\
\hline & Tempat Ibadah & 2,5 & 2,5 & 0 \\
\hline & \multirow{2}{*}{ Perumahan } & 1,8 & 1,0 & 44,47 \\
\hline & & 2,1 & 1,2 & 44,54 \\
\hline & \multirow{2}{*}{ Perdagangan dan Jasa } & 2,5 & 1,4 & 44,49 \\
\hline & & 4,5 & 2,5 & 44,51 \\
\hline \multirow{7}{*}{ Segmen 4} & $\begin{array}{l}\text { Rumah Sakit dan Fasilitas } \\
\text { Perawatan }\end{array}$ & 1,8 & 1,8 & 0 \\
\hline & Sarana Pendidikan & 2,4 & 2,4 & 0 \\
\hline & Militer & 1,0 & 1,0 & 0 \\
\hline & Perdagangan dan Jasa & 2,5 & 0,6 & 74,90 \\
\hline & \multirow{2}{*}{ Perumahan } & 1,8 & 0,5 & 74,99 \\
\hline & & 2,1 & 0,5 & 74,90 \\
\hline & Zona Campuran & 2,1 & 0,5 & 74,90 \\
\hline
\end{tabular}

Sumber: Hasil Analisis Data (2017)

\section{KESIMPULAN}

Berdasarkan hasil penelitian yang telah dilakukan, dapat disimpulkan bahwa tingkat pelayanan jalan di Koridor Jalan Godean pada kondisi eksisting masih sangat rendah dengan nilai VCR yang sangat tinggi, yaitu berkisar antara 0,93 hingga 1,15. Tingkat pelayanan jalan pada kondisi eksisting memiliki kecenderungan bahwa semakin dekat dengan Kota Yogyakarta maka semakin buruk tingkat pelayanan jalannya.Tingkat pelayanan jalan hasil pemodelan pembangunan sesuai RDTR menunjukkan bahwa ketentuan intensitas bangunan yang sudah direncanakan belum sesuai dengan kapasitas jalan yang ada. Potensi bangkitan dan tarikan transportasi yang terjadi di masa mendatang sesuai RDTR tidak dapat ditampung oleh kapasitas jalan yang tersedia. Terjadi penurunan tingkat pelayanan jalan di Segmen 4 serta tingkat pelayanan jalan yang sama buruknya dengan kondisi eksisting di Segmen 2, sedangkan di segmen 1 dan segmen 3 justru terjadi peningkatan tingkat pelayanan jalan, dan tingkat pelayanan jalan dengan simulasi pembangunan angkutan massal menunjukkan bahwa moda transportasi monorail dan trem model 2 mampu menurunkan nilai VCR. Pemodelan dengan monorail mampu meningkatkan tingkat pelayanan jalan hingga masuk kategori ideal. Trem model 2 juga mampu meningkatkan tingkat pelayanan jalan, namun tingkat pelayanan jalannya belum masuk kategori ideal. Moda transportasi yang masih memungkinkan untuk dibangun yaitu monorail dan trem model 2, sedangkan trem model 1 tidak direkomendasikan karena justru menurunkan tingkat pelayanan jalan.

\section{DAFTAR PUSTAKA}

Cahyadi, A., Wacano, D., Yananto, A., \& Wijaya, M.S.(2012). Keterbatasan dan Kendala-kendala dalam Prediksi Penggunaan Lahan Masa Depan Menggunakan Metode Cellular Automata (Studi Kasus Pemodelan Prediksi Penggunaan Lahan DAS Darang Tahun 2015). Prosiding Seminar Nasional Pengelolaan Sumberdaya Alam dan Lingkungan. Semarang: Universitas Diponegoro.

Cahyadi, A., Nugraha, H., Nurjani, E., Yananto, A. \& Wijaya, M.S.(2012) Using Remote Sensing MultiTemporal Image to Analyse the Land Use Changes and Its Impact on The Peak Discharge in Garang 
Watershed Central Java. Jurnal Matematikan, Sains dan Teknologi, 13(2), 73-79.

Cracknell, J.A. (2000). Experience in Urban Traffic Management and Demand Management in Developing Countries. United Kingdom: Departement for International Development, World Bank.

Ekartaji, P., Yunus, H.S. \& Raharjo, N. (2014). Kajian Kualitas Lingkungan Permukiman di Daerah Pinggiran Kota Kasus di Desa Ngestiharjo, Yogyakarta. Majalah Geografi Indonesia, 28(1), 96-102.

Handoyo, J.P., Yunus, H.S. \& Sujali. (2014). Perubahan Daya Dukung Lingkungan di Wilayah Pinggiran Kota (Kasus: Kecamatan yang Berbatasan dengan Kota Yogyakarta, Tahun 1990-2008. Majalah Geografi Indonesia, 28(1), 48-64.

Indrawati, L., Hartono \& Sunarto. (2009). Klasifikasi Pohon Keputusan untuk Kajian Perubahan Penggunaan Lahan Kota Semarang Menggunakan Citra Landsat TM/ETM+. Majalah Geografi Indonesia, 23(2), 109-123.

Munardy, W.J., Asmirza, M.S. \& Talarosha, B. (2005). Hubungan Tingkat Pelayanan Jalan dengan Kinerja Halte pada Alu Lintas Angkutan Umum Studi Kasus: Jalan Gatot Subroto Medan. Jurnal Arsitektur "ATRIUM", 2(3), 24-33.

Peraturan Menteri Perhubungan Nomor KM 14 Tahun (2006) tentang Manajemen dan Rekayasa Lalulintas di Jalan.

Prakoso, B.S.E. \& Muta’ali, L. (2005). Dinamika Sistem Kota-kota dan Pemilihan Alternatif Pusat Pertumbuhan Baru di Propinsi Daerah Istimewa Yogyakarta. Majalah Geografi Indonesia, 19(2), 155-179.

Rachmawati, R. \& Kurniawan, A. (2006). Pola Pergerakan Keruangan Penduduk Pinggiran Kota dan Pengaruhnya Terhadap Konsentrasi Kegiatan di Kota Yogyakarta. Majalah Geografi Indonesia, 20(1), 20-31.

Rachmawati, R. (2008). Pengembangan Pusat Pelayanan Ekonomi di Pinggiran Kota Sebagai Alternatif Penanganan Problematik Ruang di Kota Yogyakarta. Majalah Geografi Indonesia, 22(1), 73-90.

Tamin, O.Z. (2000). Perencanaan dan Permodelan Transportasi, Edisi ke-2. Bandung: Penerbit ITB.

Titania, B. (2008). Analisis Intensitas Bangunan Koridor Jalan Raya Cimahi Berdasarkan Kapasitas Jalan. Tugas Akhir. Bandung: Fakultas Arsitektur, Perencanaan, dan Pengembangan Kebijakan, Institut Teknologi Bandung.

Wardani, D.W., Danoedoro, P. \& Susilo, B. (2016). Kajian Perubahan Penggunaan Lahan Berbasis Citra Penginderaan Jauh Resolusi Menengah dengan Metode Multi Layer Perceptron dan Markov Chain. Majalah Geografi Indonesia, 30(1), 9-18.

Zuharnen. (1992). Studi Kepadatan Lalu-lintas pada Ruas Jalan Malioboro Yogyakarta Menggunakan Foto Udara Sederhana. Majalah Geografi Indonesia, 6(9), 15-25. 